Check for updates

Cite this: RSC Adv., 2017, 7, 48777

Received 18th August 2017

Accepted 12th October 2017

DOI: 10.1039/c7ra09131a

rsc.li/rsc-advances

\section{Reversible mechanofluorochromism and acidochromism using a cyanostyrylbenzimidazole derivative with aggregation-induced emission $\uparrow$}

\begin{abstract}
Yong Zhan, ${ }^{a}$ Quanpeng Wei, ${ }^{\mathrm{a}}$ Jinyu Zhao ${ }^{\mathrm{b}}$ and Xiaojing Zhang (D) *a
A novel $D-\pi-A$ structure triphenylamine functionalized benzimidazole derivative TBM was designed and synthesized. It was found that the compound TBM exhibited typical aggregation-induced emission (AIE) characteristic. It was proved by the fact that the aggregates emitted strong yellow light in THF/water with high water fraction, while it was almost non-emissive in THF. More interestingly, the TBM showed multi-stimuli responsive fluorescent behaviors. First, TBM showed significant solvatochromic effect, with emission color tuning from green to orange by changing the solvent from nonpolar hexane to polar dimethyl sulfoxide. Second, TBM exhibited reversible mechanofluorochromism. The pristine crystal of TBM emitting yellow fluorescence could be transformed into powder emitting an orange emission upon grinding, and it could be restored when the ground powder were fumed with methanol vapor. XRD and DSC results demonstrated that the reversible mechanofluorochromism was due to the transformation between the crystalline and amorphous states, which could be ascribed to its different molecular stacking mode in the solid state. Finally, we found that the TBM revealed remarkable acid-induced fluorescence quenching effect in solution and film, and the emission of TBM in $\mathrm{CHCl}_{3}$ could be quenched by trifluoroacetic acid (TFA) significantly. This work offered cyanostyrylbenzimidazole derivative that could be used as sensitive fluorescent indicator for mechanical sensors and organic acids.
\end{abstract}

\section{Introduction}

Luminescent organic compounds are highly desirable for the development of areas such as organic light-emitting diodes (OLEDs), bio-sensing, bio-imaging, chemosensors and mechano-sensors. ${ }^{1}$ In particular, mechanofluorochromic (MFC) materials exhibiting switchable colors in response to external mechanical stimuli (grinding, rubbing or crushing) are attracting substantial attention due to their potential applications in the fields of mechano-sensors, optical recording, security papers, optoelectronic devices and data storage. ${ }^{2,3} \mathrm{~A}$ fluorescence color change indicates a control of reversible conversion of molecular packing because solid-state optical properties strongly depend on molecular packing arrangements., ${ }^{4,5}$ High solid-state fluorescence efficiency plays an important role in the applications of MFC materials. However, conventional organic compounds are usually weakly emissive or

\footnotetext{
${ }^{a}$ Key Laboratory of Structure-Based Drug Design and Discovery of Ministry of Education, Shenyang Pharmaceutical University, Shenyang, 110016, P. R. China. E-mail: zhangxiaojing2046@126.com; Tel: +86-024-43520251

${ }^{b}$ College of Chemistry, Jilin University, Changchun, 130012, P. R. China

$\dagger$ Electronic supplementary information (ESI) available: ${ }^{1} \mathrm{H}-\mathrm{NMR},{ }^{13} \mathrm{C}-\mathrm{NMR}$, IR and HR-MS spectra; photophysical data in various solvents; UV-vis spectra in the mixtures of THF and water; reversibility of MFC processes; Stern-Volmer plot towards TFA in $\mathrm{CHCl}_{3}$. For ESI and crystallographic data in CIF or other electronic format. See DOI: 10.1039/c7ra09131a
}

even non-emissive in the solid state through the aggregation caused quenching (ACQ) effect. ${ }^{6}$ Consequently, the MFC phenomenon becomes difficult to observe. In 2001, Tang's group reported aggregation-induced emission (AIE) materials, an important kind of anti-ACQ materials that exhibited strong emission in poor solvents or in the solid state. ${ }^{7}$ Till now, more number of AIE-active materials has been reported in many literatures. It is fascinating that some MFC luminogens are AIE active. For example, tetraphenylethylene derivatives are a typical kind of MFC materials with AIE as reported by the groups of Tang, Chi, and others. ${ }^{8-10}$ Boron diketonates/diiminates with AIE activities showing reversible mechanofluorochromism was reported by Fraser's and Chujo's groups. ${ }^{11}$ Yang and co-workers reported a novel class of AIE dyes based on 9,10-bis(arylvinyl) anthracene showed MFC behaviors. ${ }^{12}$ Therefore, AIE has been considered a key for opening a treasure chest of potential MFC materials. ${ }^{13}$

Currently, extended $\pi$-conjugated molecules with a $\mathrm{D}-\pi-\mathrm{A}$ structure have attracted remarkable interest because of their flexibility for creating organic emitters with tunable emission. ${ }^{14}$ The cyano group, due to its strong electron withdrawing ability is an ideal candidate for an excellent acceptor featuring controllable photophysical properties. ${ }^{15}$ Moreover, the cyanosubstituted derivatives due to large steric hindrance result in their twisted conformation. Therefore, they usually reveal weak emission or are non-emissive in solution and emit enhanced 


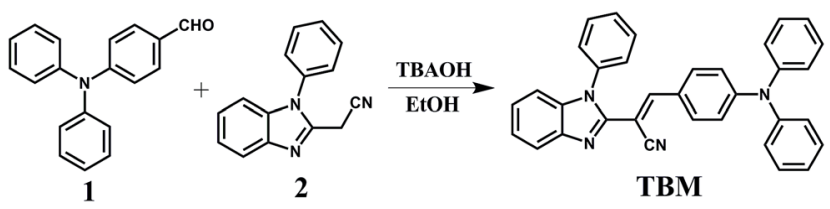

Scheme 1 The synthetic route for TBM.

fluorescence in the solid state. ${ }^{16}$ Thus, ICT dyes with AIEactive materials are expected to become a foundation for MFC materials. In order to achieve novel smart materials with multi-stimuli responsive characteristics, we designed and synthesized a new $\mathrm{D}-\pi-\mathrm{A}$ type triphenylamine modified benzimidazole derivative TBM (Scheme 1). The molecular design was based on the following points. First, the introduction of triphenylamine (TPA) was due to its strong electron-donating ability and propeller-shaped structural motif would prevent interaction and helpful for generating MFC behaviors. Second, cyanostyryl derivatives usually showed AIE characteristic with strong fluorescence in the aggregated states or solid state. Third, $N$-phenylbenzimidazole was employed as acid-sensitive group on account of its alkalinity. Finally, the TPA was electron donor, and the $\mathrm{D}-\pi-\mathrm{A}$ characteristic would change if the benzimidazole protonated with trifluoroacetic acid (TFA). The photophysical properties of compound TBM were investigated. The TBM was weakly emissive in solutions whereas strong emission was observed in the aggregated state due to aggregation induced emission. Moreover, the target compound TBM was found to exhibit multi-stimuli responsive behaviors. First, due to its strong ICT characteristics, the compound TBM showed significant solvatochromic effects. Second, TBM exhibited a change in fluorescence color from yellow to orange after grinding and could revert to the original state by treatment with solvent vapors. Third, we found that the compound TBM exhibited acidochromism, its fluorescent emission could be quenched by TFA significantly. Above results revealed that the compound TBM has potential applications in sensors and optoelectronic devices.

\section{Experimental section}

\section{Materials and measurements}

Absolute ethanol was distilled over magnesium and iodine. The other chemicals and reagents and solvents were used as received without further purification. ${ }^{1} \mathrm{H}$ NMR spectra and ${ }^{13} \mathrm{C}$ NMR spectra were carried out on a Bruker AMX-400 NMR spectrometer at $600 \mathrm{MHz}$ and $150 \mathrm{MHz}$ in DMSO- $\mathrm{d}_{6}$ as the solvent at room temperature. HRMS analysis was carried out on an Agilent 6500 Q-TOF mass spectrometer (Version Q-TOF B.05.01). FT-IR spectra were measured with a Nicolet-360 FTIR spectrometer by the incorporation of samples in $\mathrm{KBr}$ disks. The frontier orbital plots of the HOMO and LUMO of target compound were obtained by density functional theory (DFT) calculations at the B3LYP/6-31G level with the Gaussian 09W program package. The UV-vis absorption spectra were obtained on a Beijing purkinje TU-1810 Spectrophotometer. Fluorescence emission spectra were determined on a Shimadzu RF-5301 PC fluorimeter. The fluorescence quantum yields in different solvents were estimated by comparing to a standard (9,10-diphenylanthrance in benzene, $\left.\Phi_{\mathrm{f}}=0.85\right)$. Powder X-ray diffraction (XRD) measurements were carried out with a Bruker Advance D8 X-ray diffractometer. DSC measurements were carried out using a Mettler Toledo 3 thermos system at a heating rate of $10{ }^{\circ} \mathrm{C} \mathrm{min}^{-1}$ under $\mathrm{N}_{2}$ atmosphere.

\section{Preparation of aggregates for AIE measurement}

The THF/water mixtures with different water fractions were prepared by slowly adding distilled water into solutions of the target molecule in THF under sonication at room temperature, the concentration was maintained at $10 \mu \mathrm{M}$. The emission measurement of the resultant mixtures was performed immediately.

\section{Preparation of the samples for mechanofluorochromism study}

The ground powder was obtained by grinding the pristine crystal with a pestle in the mortar. The fumed sample was prepared by fuming the ground powder with methanol vapor for 1 min.

\section{Synthetic procedures and characterizations}

Compound $\mathbf{1}$ and $\mathbf{2}$ were synthesized by the procedures reported previously. ${ }^{17}$

(E)-3-(4-(Diphenylamino)phenyl)-2-(1-phenyl-1H-benzo $[d]$ imidazol-2-yl)acrylonitrile (TBM). 2-(1-Phenyl-1H-benzo[ $d]$ imidazol-2-yl)acetonitrile $(0.98 \mathrm{~g}, 4.2 \mathrm{mmol})$ and 4 -(diphenylamino)benzaldehyde (1.15 g, $4.2 \mathrm{mmol}$ ) were dissolved in absolute ethanol $(40 \mathrm{~mL})$. The mixture was heated to reflux for $1.5 \mathrm{~h}$, and then a few drops of tetrabutylammonium hydroxide (TBAOH, 2 M solution in water) were added. After the mixture was further refluxed for $10 \mathrm{~h}$, and then was cooled to room temperature, yellow solid was obtained after filtration and washing by ethanol $(3 \times 5 \mathrm{~mL})$. The crude product was purified by column chromatogram (silica gel, petroleum ether/dichloromethane, $\mathrm{v} / \mathrm{v}=1 / 5$ ) to obtain TBM $1.40 \mathrm{~g}$ as yellow solid in a yield of $68 \%$. Mp: $151{ }^{\circ} \mathrm{C}$ (obtained from DSC). ${ }^{1} \mathrm{H}$ NMR (600 MHz, TMS, DMSO- $\left.\mathrm{d}_{6}\right) \delta=7.82-7.78$ $(\mathrm{m}, 1 \mathrm{H}), 7.75(\mathrm{~d}, J=9.6 \mathrm{~Hz}, 1 \mathrm{H}), 7.72-7.64(\mathrm{~m}, 1 \mathrm{H}), 7.61-7.55$ (m, 1H), 7.54-7.48 (m, 2H), 7.42-7.38 (m, 2H), 7.36-7.33 (m, $4 \mathrm{H}), 7.29(\mathrm{~d}, J=7.8 \mathrm{~Hz}, 2 \mathrm{H}), 7.22-7.17(\mathrm{~m}, 1 \mathrm{H}), 7.17-7.14(\mathrm{~m}$, $2 \mathrm{H}), 7.08(\mathrm{~d}, J=7.8 \mathrm{~Hz}, 3 \mathrm{H}), 6.88-6.86(\mathrm{~m}, 2 \mathrm{H}), 6.63(\mathrm{~d}, J=$ $9.0 \mathrm{~Hz}, 2 \mathrm{H})$ (Fig. S9†); ${ }^{13} \mathrm{C}$ NMR $(150 \mathrm{MHz}$, DMSO-d 6 ) $\delta(\mathrm{ppm})$ $=151.29,150.59,146.05,144.97,142.85,135.69,134.81$, $131.83,130.36,130.28,130.10,129.27,127.88,126.56,126.44$, 126.19, 125.64, 125.36, 125.11, 124.84, 123.64, 120.38, 119.56, 118.87, 111.31, 97.73, 56.40, 18.94 (Fig. S10†); IR (KBr, $\left.\mathrm{cm}^{-1}\right)$ : 3429, 2925, 1632, 1404, 1385, 1271, 1009, 982, 833, 703 (Fig. S11 $\dagger$ ); HRMS (ESI $\dagger$ ): $m / z=488.2001$, found: 489.2083 [M $+\mathrm{H}]^{+}$(Fig. S12†). 


\section{Results and discussion}

Synthesis

The synthetic route for TBM is shown in Scheme 1. Firstly, compounds 4-(diphenylamino)benzaldehyde 1 and 2-(1-phenyl$1 H$-benzo $[d]$ imidazol-2-yl)acetonitrile 2 were prepared according to the reported methods. The Knoevenagel condensation reaction between compound $\mathbf{1}$ and $\mathbf{2}$ in the presence of TBAOH afforded TBM in a yield of $68 \%$. The target compound was characterized by ${ }^{1} \mathrm{H}$ NMR, ${ }^{13} \mathrm{C}$ NMR spectroscopy, FT-IR and high-resolution mass spectrometry (HRMS). In the FT-IR spectrum of TBM, the vibration absorption band appeared at $c a .982 \mathrm{~cm}^{-1}$, suggesting that $\mathrm{C}=\mathrm{C}$ bond is in trans-form. Meanwhile, the peaks at 7.416 and $7.389 \mathrm{ppm}$ in the ${ }^{1} \mathrm{H}$ NMR spectrum from the vinyl group protons had a large coupling constant of $16.2 \mathrm{~Hz}$, indicating that the vinyl group had a transformation. ${ }^{18}$ In addition, the target compound TBM showed good solubility in common solvent, including $\mathrm{CH}_{2} \mathrm{Cl}_{2}, \mathrm{CHCl}_{3}$, THF, DMF and DMSO.

\section{Photophysical properties in solutions}

The UV-vis absorption and fluorescence emission spectra of TBM in different solvents $\left(1.0 \times 10^{-5} \mathrm{M}\right)$ are shown in Fig. 1, and the corresponding photophysical data are listed in Table S1
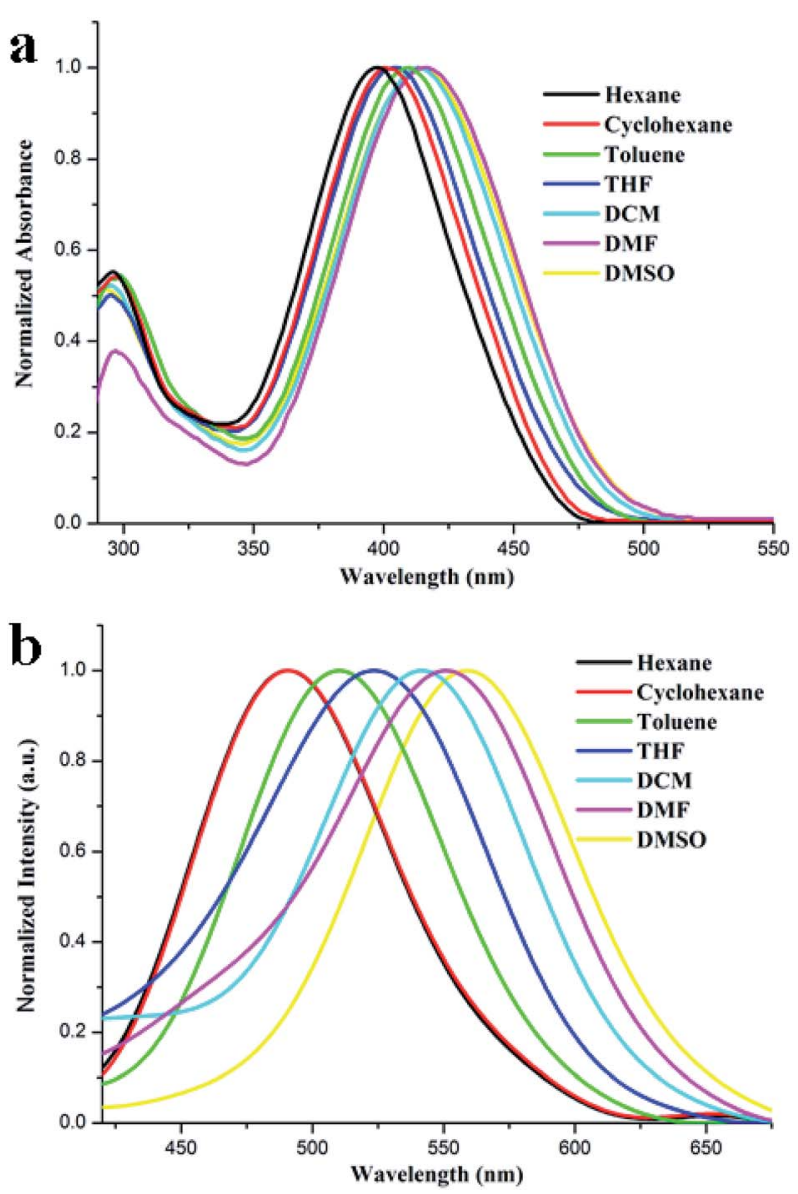

Fig. 1 Normalized UV-vis absorption (a) and fluorescent emission (b, $\lambda_{\text {ex }}=365 \mathrm{~nm}$ ) spectra of TBM excited at $410 \mathrm{~nm}$ in different solvents $\left(1.0 \times 10^{-5} \mathrm{M}\right)$.
(ESI $\dagger$ ). As shown in Fig. 1a, the absorption bands of TBM in dilute THF appeared at $c a .295 \mathrm{~nm}$ and $c a .404 \mathrm{~nm}$. The absorption band at ca. $295 \mathrm{~nm}$, which did not shift with increasing polarity of the solvent, could be originated from the $\pi-\pi^{*}$ transition. And the other strong absorption band at $c a$. $404 \mathrm{~nm}$ was derived from an intramolecular charge transfer (ICT) transition, which could be confirmed by the solventdependent emission spectra. The maximum absorption band of TBM was located at $397 \mathrm{~nm}$ in hexane, and red-shifted gradually with increasing polarity of the solvent. It reached $416 \mathrm{~nm}$ in DMSO (Table S1, ESI $\dagger$ ). The solvent-dependent fluorescence emission spectra of TBM in various solvent were shown in Fig. 1b, it was clear that with increasing the polarity of the solvent, the emission spectra of TBM red-shifted significantly and became broad, meanwhile, Stokes shift was also increased dramatically. For instance, TBM exhibited a strong emission band at $490 \mathrm{~nm}$ in hexane and its Stokes shift was $4781 \mathrm{~cm}^{-1}$, and with increasing solvent polarity, its emission band and Stokes shift reached $560 \mathrm{~nm}$ and $6181 \mathrm{~cm}^{-1}$ in DMSO, respectively, accompanied by emission bands broaden. Therefore, the significant red-shift of the emission band and the large Stokes shifts in polar solvents compared with those in nonpolar solvents and solvent polarity demonstrated that an ICT characteristic for the excited state. ${ }^{19}$ These results in the absorption and fluorescence spectra imply that TBM is a typical $\mathrm{D}-\pi-\mathrm{A}$ molecule and the absorption band around $400 \mathrm{~nm}$ is originated from ICT transition.

The fluorescence quantum yield $\left(\Phi_{\mathrm{f}}\right)$ in various solvents was measured using 9,10-diphenylanthracene in benzene $\left(\Phi_{\mathrm{f}}=0.85\right)$ as the standard (Table S1, ESI $\dagger$ ). It was found that TBM exhibited very low $\Phi_{\mathrm{f}}(<0.02)$ in the tested solvents with different polarity. The low $\Phi_{\mathrm{f}}$ value in solution might be ascribed to the presence of cyano group induced compound emitting weak fluorescence.

\section{Theoretical calculation}

The ICT characteristic of the compound TBM is further supported by the density functional theory (DFT) calculations by Gaussian 09W program using the DFT/B3LYP/6-31G(d) method. The frontier orbital plots of the HOMO and LUMO are shown in Fig. 2. It was found that the highest occupied molecular orbital (HOMO) of TBM was mainly localized on the electron-donor triphenylamine moiety, partially located on benzimidazole unit, whereas the lowest unoccupied molecular orbital (LUMO) was mainly distributed in the electron-acceptor of cyanostyryl moiety. Therefore, the spatial separation between the HOMO and the LUMO indicated a typical ICT characteristic in the molecule in accordance with spectroscopic results. ${ }^{20}$ Additionally, it was found that the molecule TBM adopted twisted conformation at its optimized lowest energy states. Therefore, the moderately twisted skeleton disfavored close molecular packing in the solid state and this might endow TBM with both AIE-active and MFC behaviors.

\section{Aggregation-induced emission investigation}

The THF solution of TBM emitted weak fluorescence, but the yellow crystal showed extremely strong fluorescence under 


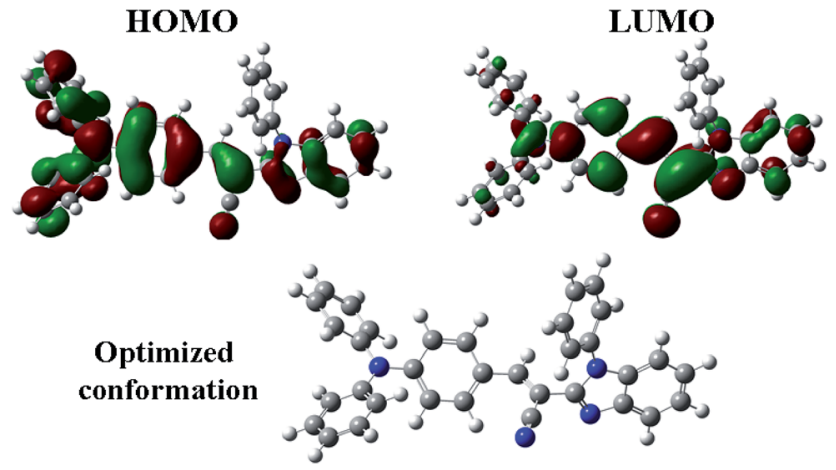

Fig. 2 Electron density distributions in the HOMO and LUMO states of TBM calculated by DFT in Gaussian 09 at the B3LYP/6-31G(d) level.

$365 \mathrm{~nm}$ illumination, which revealed that the compound TBM might be AIE molecule (Fig. S1, ESI $\dagger$ ). To further check the AIE behavior of the compound TBM, the fluorescent emission spectra in the mixtures of THF and water with different volume contents of water $\left(f_{\mathrm{w}}\right.$, the volume percentage of water in THF/ $\mathrm{H}_{2} \mathrm{O}$ mixture) were investigated. Small aggregates were prepared in THF by gradually increasing the water fraction. The different percentage of water fraction was required for compound TBM to initiate the AIE effect. As shown in Fig. 3, in dilute THF solution, TBM exhibited green fluorescence with the maximum wavelength at $520 \mathrm{~nm}$, but the intensity was very weak and quantum yield $\left(\Phi_{\mathrm{f}}\right)$ was only $0.4 \%$ (Table S1, ESI $\dagger$ ). When proper amount of water was added into THF solution, the emission peak initially decreased and showed a red shift due to the increase of the solvent polarity, which was ascribed to the ICT effect in polar solvent for TBM with a D-A structure. ${ }^{21}$ Moreover, when $f_{\mathrm{w}}$ was $\leq 70 \%$, only weak emission peaks were observed, which was attributed to the solvating powers of the mixtures still genuinely dissolve the luminogenic molecules. When $f_{\mathrm{w}}$ was above $80 \%$, the emission was restored and the emission intensity of TBM began to increase rapidly. The absorption spectra suggested that TBM molecule started to aggregate while the fraction of water exceeds $80 \%$ (Fig. S2, ESI $\dagger$ ), indicating that emission enhancement was ascribed to molecular aggregation. ${ }^{22}$ As $f_{\mathrm{w}}$ was $90 \%$, the corresponding fluorescent intensity was enhanced by up to almost 5.2 times in comparison with that at $f_{\mathrm{w}}=0 \%$. The bright yellow green emitting (centered at $542 \mathrm{~nm}$ ) could be ascribed to the formation of aggregates. Owing to the increasing polarity of the solvent mixtures, the emission exhibited a clear red-shifted. These results indicated that cyano moiety with large steric hindrance could indeed help molecule to achieve AIE characteristic. $^{23}$

\section{Mechanoflurochromism in the solid state}

The strong solid-state fluorescence and the possibility of MFC properties encouraged us to study the MFC behaviors. In our previous study, we found that the propeller-shaped AIE luminophore with the ICT effect was a valuable strategy to design MFC materials. ${ }^{24}$ Moreover, the result of previous quantum mechanical computation indicated that the cyano group could enhance the distortion degree of the molecule because of steric
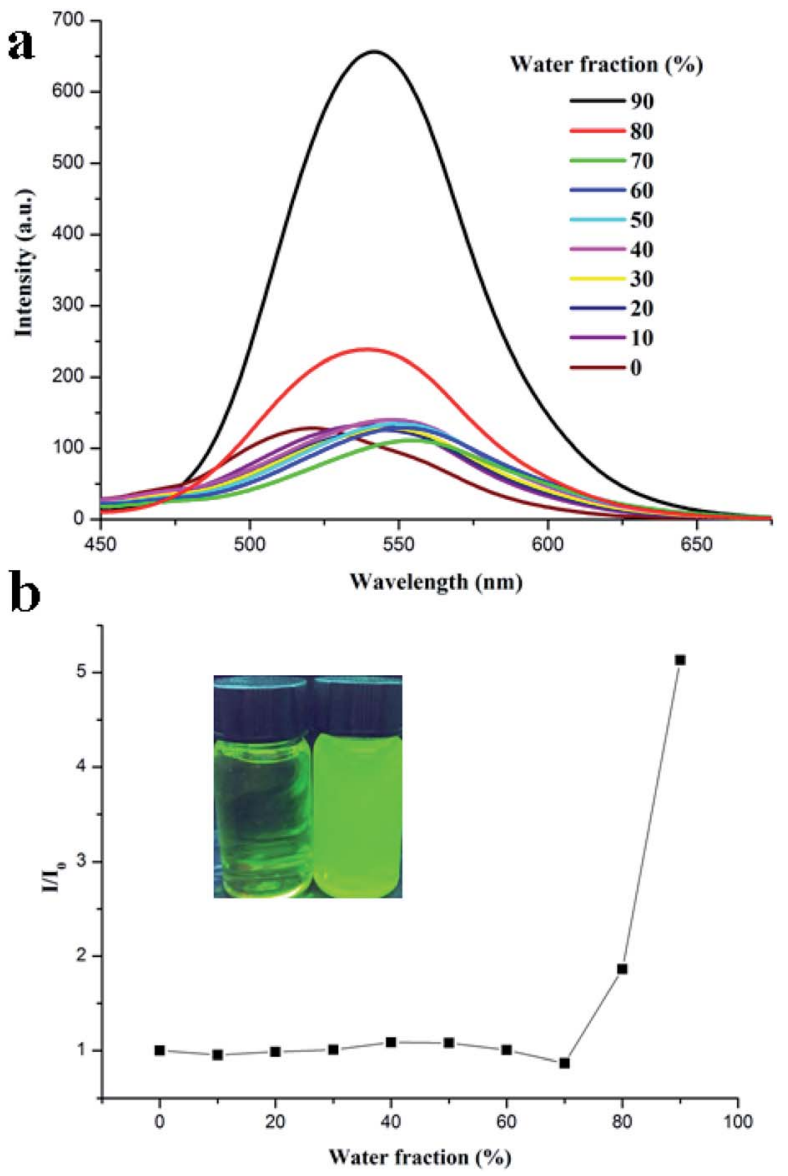

Fig. 3 (a) Fluorescence spectra of TBM in the mixtures of THF and water with different water fractions $\left(f_{\mathrm{w}}\right)$; (b) normalized fluorescence emission intensity of TBM in THF/water with different $f_{\mathrm{w}}$. Concentration: $1.0 \times 10^{-5} \mathrm{M}$; $\lambda_{\mathrm{ex}}=410 \mathrm{~nm}$; inset is the fluorescence images of TBM in THF and THF/water $\left(f_{\mathrm{w}}=90 \%\right)$ under $365 \mathrm{~nm}$ illumination.

hindrance. Therefore, we can infer that the MFC behaviors of the compound TBM are related to its distortion degrees. Herein, we tried to investigate the MFC behaviors of the compound TBM and found that TBM showed different fluorescence emitting behaviors upon the treatment of grinding and fuming. As shown in Fig. 4, the pristine crystal of TBM emitted bright yellow fluorescence with emission peak at $c a .532 \mathrm{~nm}$. Upon grinding using a mortar and pestle, the pristine crystal converted to orange fluorescence and the emission peak red-shifted to $549 \mathrm{~nm}$. When the ground powder was fumed with methanol vapor for $1 \mathrm{~min}$, the fluorescence emission of the ground powder restored to its original state. If the fumed powder of TBM was reground, its emission red-shifted to $550 \mathrm{~nm}$ again. This MFC conversion could be repeated many times without fatigue, as these stimuli did not cause any chemical change (Fig. S3, ESI $†$ ). Thus, the MFC property of a compound can be significantly improved simply by introducing a cyano group into its molecular structure.

To evaluate the difference of the solid-state fluorescence behaviors between pristine crystal and amorphous states, the phase transition characteristics of TBM were investigated by powder X-ray diffraction (XRD) and differential scanning calorimetry (DSC). The XRD diffractograms of the pristine crystal 
$\mathbf{a}$
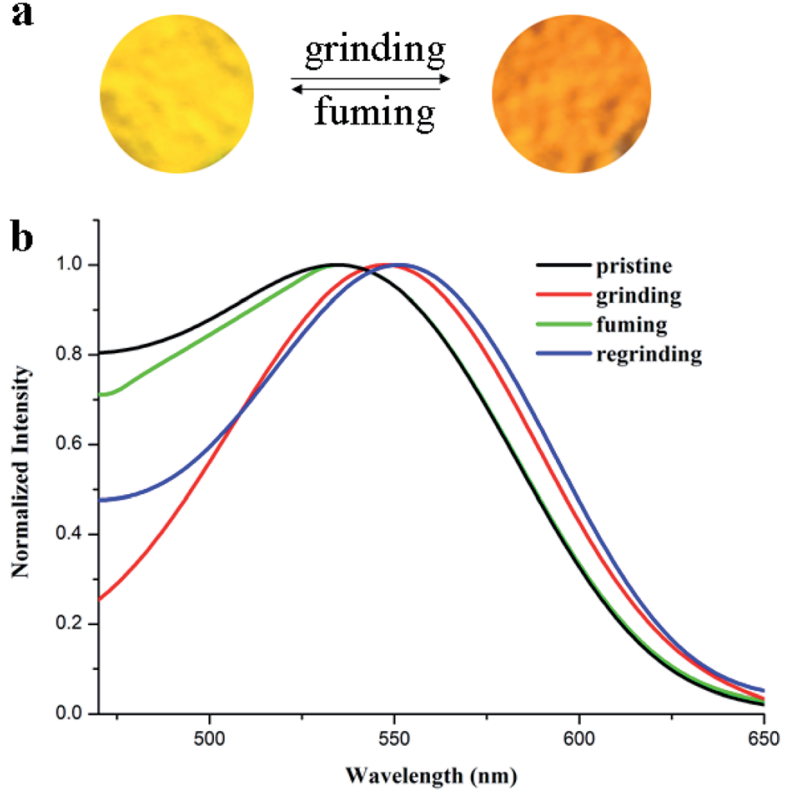

Fig. 4 (a) Photos of TBM changes under grinding and fuming stimuli; (b) normalized fluorescence spectra of TBM in different solid-states: pristine, grinding, fuming and regrinding, $\lambda_{\text {ex }}=410 \mathrm{~nm}$.

exhibited intense and sharp reflection peaks, indicative of their well-ordered crystalline natures. In contrast, after grinding, the diffraction peaks disappeared and only a diffuse band was observed, which implied that grinding led to a crystalline to amorphous phase conversion of solids (Fig. 5). After exposing the ground samples to methanol vapor, the sharp and intense diffraction peaks reappeared. Their reappearance demonstrated that the amorphous powder restored its pristine crystallinity upon solvent fumigation. Thus, the powder XRD results revealed that the MFC mechanism of TBM could be ascribed to a morphological transition between crystalline and amorphous states upon the ground/fumed process. Ground-induced structural transition character of TBM probably leaded to changes in packing, which allowed a more planar structure and perhaps better dipole-dipole intermolecular interactions, leading to a red shift of fluorescence. ${ }^{25}$

To further reveal the effect of heating on the MFC behaviors, the DSC curves of TBM in different solid state are shown in Fig. S4 (ESI†). The DSC curves of the pristine crystal of TBM exhibited strong endothermic peak at $151^{\circ} \mathrm{C}$, corresponding to its melting point, while other one broad exothermic transition peak appeared at $60{ }^{\circ} \mathrm{C}$ in the ground powder of TBM, which could be ascribed to the cold-crystallization (crystallizing from glass state) of ground TBM powder upon annealing ${ }^{26}$ and also confirmed that the amorphous state was a metastable state. As a result, we deduced that the emitting color changes were due to the transformation between the crystalline and amorphous state. In addition, TBM in pristine and ground conditions have an endothermic transition before the melting point, which could be attributed to a crystal phase transition. ${ }^{27}$ However, the reason for TBM exhibiting this transition is still unclear, and this phenomenon requires further research.

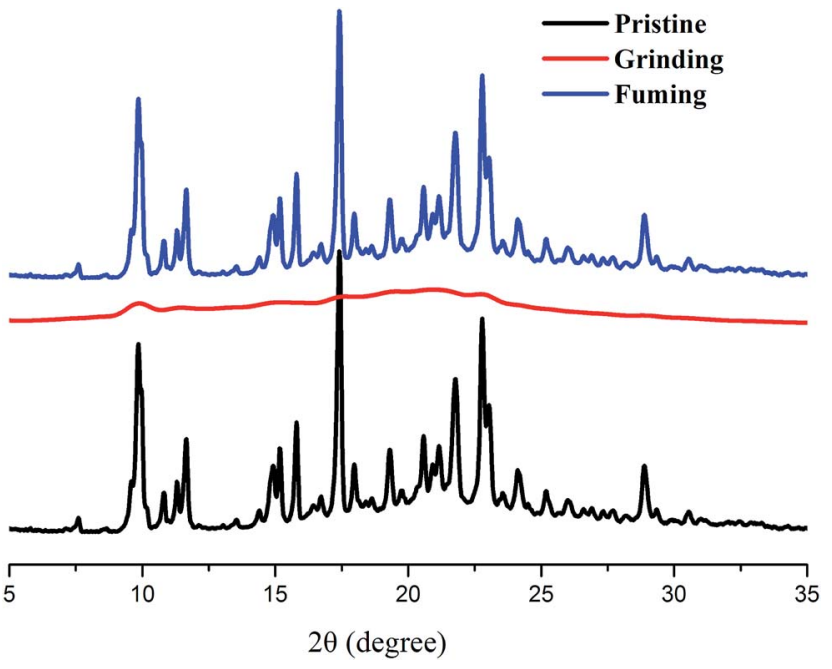

Fig. 5 XRD patterns of TBM in different solid-states: pristine, grinding and fuming.

\section{Acidochromic properties in solution}

Acidochromism is different from the mechanochromism which can be induced by the change in the electronic delocalization in a molecule by acidification. ${ }^{28}$ Generally the molecules having nitrogen hetero atom are responsible for acidochromism because of the availability of the lone pair of electrons on the nitrogen to bind with protons. In order to achieve acidochromic properties in solution, we analyzed the proton sensing ability of the compound TBM, which was attributed to the terminal benzimidazole moiety that had a good capacity of combining with proton. The TBM exhibited yellow fluorescence in $\mathrm{CHCl}_{3}$, when TFA was gradually added to the $\mathrm{CHCl}_{3}$ solution, the solution by degrees converted into a dark red one (see insets of Fig. 6). In order to reveal the fluorescent sensory mechanism of TBM towards TFA and investigate the possible acidochromic properties of TBM, the spectral response abilities of TBM towards TFA in $\mathrm{CHCl}_{3}\left(2.5 \times 10^{-5} \mathrm{M}\right)$ were investigated (Fig. 6). As shown in Fig. 6a, the absorption band at $c a .420 \mathrm{~nm}$ for TBM decreased gradually and a new absorption band located at $c a .482 \mathrm{~nm}$ emerged and increased gradually with increasing amounts of TFA. Moreover, the appearance of an isometric point at $c a .447 \mathrm{~nm}$ meant a new species was formed from TBM induced by TFA. We deduced that TBM was protonated by TFA. The protonated benzimidazole showed stronger electron withdrawing ability than benzimidazole, so that new absorption at low-energy region appeared. ${ }^{29}$ Considering the new absorption at $c a .482 \mathrm{~nm}$ and the existence of one isometric point, TFA-protonated TBM in $\mathrm{CHCl}_{3}$ formed the cation $\mathbf{T B M}-\mathbf{H}^{+}$. The fluorescence of $\mathbf{T B M}$ in $\mathrm{CHCl}_{3}$ solution could respond to proton. The fluorescent spectral changes of TBM in $\mathrm{CHCl}_{3}$ solution towards TFA are shown in Fig. 6b. It was clear that the maximum emission band at $c a .533 \mathrm{~nm}$ for $\mathbf{T B M}$ in $\mathrm{CHCl}_{3}$ solution decreased when TFA was added. The higher was the concentration of TFA, the higher was the fluorescence quenching efficiency. The emission was quenched by $37 \%$ under additional 50 equiv. TFA, at which point the solution still emitted yellow fluorescence (centered at $c a .539 \mathrm{~nm}$ ). When 500 equiv. of TFA 

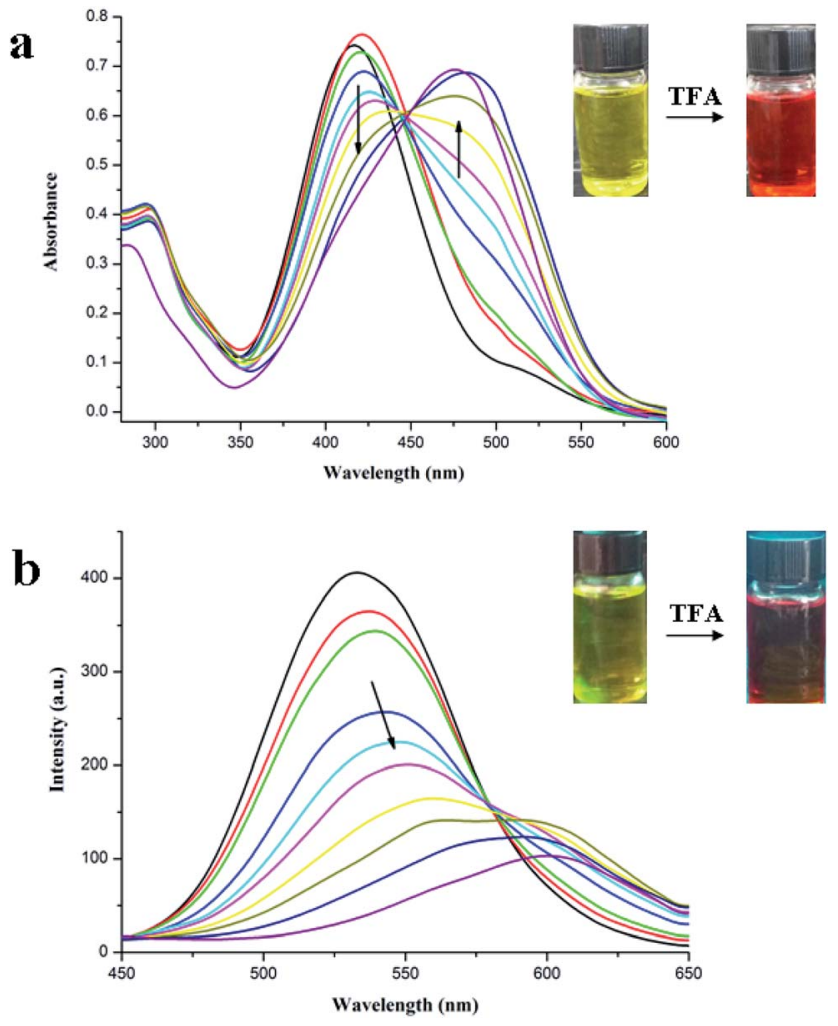

Fig. 6 (a) UV-vis absorption and (b) fluorescent emission spectral changes of TBM in $\mathrm{CHCl}_{3}$ from 0 equiv. to 500 equiv. with additional TFA at room temperature. The concentration of TBM was maintained at $2.5 \times 10^{-5} \mathrm{M}$; excitation wavelength is $410 \mathrm{~nm}$. Insert: images of TBM in $\mathrm{CHCl}_{3}$ before and after adding TFA.

was added, the emission quenching efficiency reached $75 \%$. Meanwhile, we could find that the solution emitted a very weak red fluorescence with new peak appearing at ca. $600 \mathrm{~nm}$. The yellow fluorescence of TBM could be quenched significantly by TFA. Therefore, the protonated benzimidazole displayed stronger electron withdrawing ability, so that absorption band red-shifted and the emission quenching happened on account of the occurrence of photo-induced electron transfer from triphenylamine unit to protonated benzimidazole. ${ }^{30}$ The above results indicated that TBM solutions could respond to proton in terms of color and fluorescence, and displayed significant acidochromic behaviors, so the TBM solution could also detect TFA by naked eyes.

The interactions of the compound TBM with TFA were further comfirmed by ${ }^{1} \mathrm{H}$ NMR spectral analysis in the absence and presence of TFA. As shown in Fig. S5 (ESI $\dagger$ ), we found that the addition of TFA caused the signals to show an obvious downfield shift for protons, particularly at the benzimidazole ring. This result proved that the proton binding of TBM might be ascribed to protonation of the nitrogen atom in the benzimidazole unit to form a cation TBM-H ${ }^{+}$(Fig. S5, ESI $\dagger$ ), which reduced the electron density around all protons, enhanced the electron withdrawing ability of the benzimidazole moiety.

The change in optical properties induced by TFA could be recovered by the addition of TEA (triethylamine) (Fig. S6 $\dagger$ ).

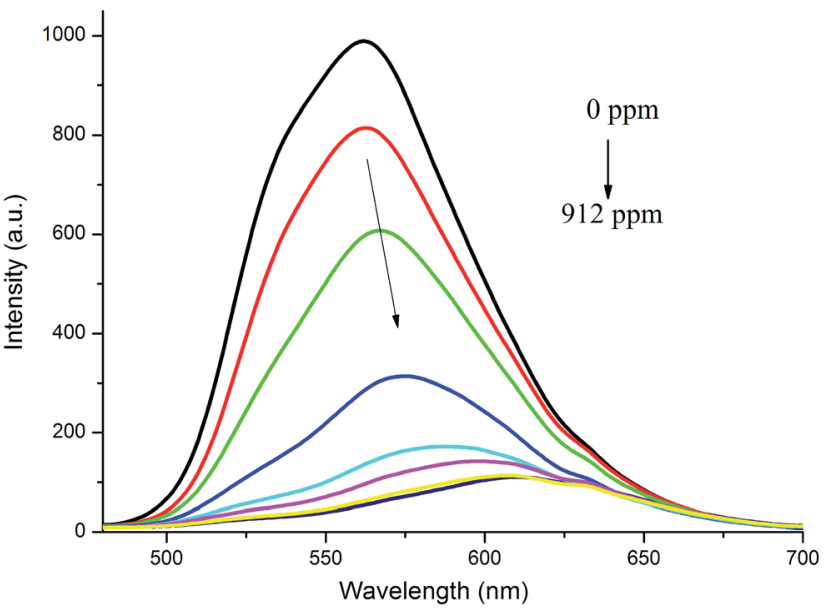

Fig. 7 Fluorescence spectra of TBM-based film upon exposure to different amounts of TFA vapor $\left(\lambda_{\mathrm{ex}}=420 \mathrm{~nm}\right)$.

These changes were completely reversible on neutralization with TEA. This acidochromic behavior might be used for the development of fluorescence probe for $\mathrm{pH}$ differences in biological and environmental media. Furthermore, Stern-Volmer plot for TBM towards TFA in $\mathrm{CHCl}_{3}$ are shown in Fig. S7 (ESI $\dagger$ ), the corresponding fluorescence quenching data were calculated using the Stern-Volmer equation:

$$
F_{0} / F=1+K_{\mathrm{sv}}[Q]
$$

Where $F_{0}$ is the original emission intensity of probe prior to the addition of the quencher, $F$ is the emission intensity at given concentration of the quencher $[Q]$, and $K_{\mathrm{sv}}$ is the Stern-Volmer constant. $^{31}$ The calculated $K_{\mathrm{sv}}$ value of the aggregate of TBM towards TFA was $236 \mathrm{M}^{-1}$, suggesting interaction between the probes and TFA.

The spectrophotometric $\mathrm{pH}$ titrations were carried out to examine the spectra changes. As shown in Fig. S8 (ESI $\dagger$ ), when $\mathrm{pH}$ value decreased from 7.20 to 2.05 , the absorption at $431 \mathrm{~nm}$ declined. While a new peak at $c a .500 \mathrm{~nm}$ increased gradually. Moreover, the appearance of an isosbestic point at $453 \mathrm{~nm}$ meant a new species was formed from TBM induced by acid. The emission spectra changes depicted the same protonation process. The TBM solution emitted strong fluorescence at $544 \mathrm{~nm}$. With continuous addition of acid, the fluorescence emission was gradually quenched and red-shifted to $555 \mathrm{~nm}$. The higher was the concentration of acid, the higher was the emission quenching efficiency. The color of solution changed from light yellow to dark orange, indicating the ability of optical detection of $\mathrm{H}^{+}$ion. So benzimidazole derivatives are usually employed to modify the fluorophore to develop intracellullar pH sensor. ${ }^{32}$ For example, Gökhan et al. have reported 8substituted benzimidazole-BODIPY $\mathrm{pH}$ sensor. $^{33} \mathrm{Li}$ and coworkers have reported the benzimidazole derivatives could be used as an optical and "off-on" fluorescent $\mathrm{pH}$ indicator. ${ }^{34}$

The response of the film based on TBM with strong emission to the volatile acid was expected. As shown in Fig. 7, we found that the emission at ca. $562 \mathrm{~nm}$ of TBM-based film decreased 
upon exposed to TFA vapor. The higher was the concentration of TFA, the higher was the fluorescence quenching efficiency. When the concentration quenching of TFA vapor reached $651 \mathrm{ppm}$, the fluorescence quenching efficiency of TBM-based film reached $88 \%$, and the film with yellow emission became dark red under UV irradiation. Therefore, the film based on TBM could be quenched by TFA vapor and used as fluorescent sensory materials.

As a result, introducing cyanostyryl group and benzimidazole moiety endows the obtained molecule with multi-stimuli responsive properties. These results would provide a new strategy for better designing of multi-stimuli responsive materials with precise control over the optical and electronic behaviors for advanced applications.

\section{Conclusions}

In summary, we have synthesized new cyanostyrylbenzimidazole derivative TBM. It was found that the $\mathrm{D}-\pi-\mathrm{A}$ type molecule gave ICT emission, which was affected by the substituents on the triphenylamine as well as on the cyano moiety. Although the emission of TBM in the solution was very weak, the aggregates emitted strong yellow light in the mixture $\mathrm{THF} /$ water with high water fraction due to AIE. Interestingly, the pristine crystal of TBM emitting strong yellow light under UV irradiation could be transferred into powder emitting orange luminescence after grinding. Such mechanofluorochromism was reversible upon the treatment of grinding and fuming. XRD and DSC analysis results demonstrated that the mechanofluorochromism of TBM could be attributed to the transformation between the crystalline structure and amorphous state upon external stimuli. Moreover, TBM could be used as turn-off type fluorescent sensory materials to detect TFA in solution and film by naked eyes. These results obtained here can provide us with a new idea to open up new way of smart fluorescent materials.

\section{Conflicts of interest}

There are no conflicts to declare.

\section{Acknowledgements}

This work was supported by Scientific Research Fund of Liaoning Provincial Education Department of China (No. L2015528), Career Development Support Plan for Young and Middle-aged Teachers in Shenyang Pharmaceutical University (No. ZQN2016027), and Program for Innovative Research Team of the Ministry of Education and Program for Liaoning Innovative Research Team in University.

\section{Notes and references}

1 (a) J. Yang, Z. Ren, Z. Xie, Y. Liu, C. Wang, Y. Xie, Q. Peng, B. Xu, W. Tian, F. Zhang, Z. Chi, Q. Li and Z. Li, Angew. Chem., Int. Ed., 2017, 56, 880-884; (b) W. Wu, R. Tang, Q. Li and Z. Li, Chem. Soc. Rev., 2015, 44, 3997-4022; (c)
J. Mei, Y. Hong, J. W. Y. Lam, A. Qin, Y. Tang and B. Z. Tang, Adv. Mater., 2014, 26, 5429-5479.

2 Y. Sagawa and T. Kato, Nat. Commun., 2009, 1, 605-610.

3 Z. Chi, X. Zhang, B. Xu, X. Zhou, C. Ma, Y. Zhang, S. Liu and J. Xu, Chem. Soc. Rev., 2012, 41, 3878-3896.

4 Y. Sagara, S. Yamane, M. Mitani, C. Weder and T. Kato, $A d v$. Mater., 2016, 28, 1073-1095.

5 P. Xue, J. Ding, P. Wang and R. Lu, J. Mater. Chem. C, 2016, 4, 6688-6706.

6 S. A. Jenekhe and J. A. Osaheni, Science, 1994, 265, 765-768. 7 J. Luo, Z. Xie, J. W. Y. Lam, L. Cheng, H. Chen, C. Qiu, H. S. Kwok, X. Zhan, Y. Liu, D. Zhu and B. Z. Tang, Chem. Commun., 2001, 1740-1741.

8 (a) J. Wang, J. Mei, R. Hu, J. Z. Sun, A. Qin and B. Z. Tang, J. Am. Chem. Soc., 2012, 134, 9956-9966; (b) Y. Hong, J. W. Y. Lam and B. Z. Tang, Chem. Commun., 2009, 43324353.

9 (a) B. Xu, Z. Chi, J. Zhang, Z. Zhang, H. Li, X. Li, S. Liu, Y. Zhang and J. Xu, Chem.-Asian J., 2011, 6, 1470-1478; (b) C. Ma, X. Zhang, Y. Yang, Z. Ma, L. Yang, Y. Wu, H. Liu, X. Jia and Y. Wei, J. Mater. Chem. C, 2016, 4, 4786-4791.

10 (a) T. Jadhav, J. M. Choi, J. Shinde, J. Y. Lee and R. Misra, J. Mater. Chem. C, 2017, 5, 6014-6020; (b) H. Gao, D. Xu, X. Liu, A. Han, L. Zhou, C. Zhang, Z. Li and J. Dang, Dyes Pigm., 2017, 139, 157-165; (c) R. Misra, T. Jadhav, B. Dhokale and S. M. Mobin, Chem. Commun., 2014, 50, 9076-9078; (d) Y. Zhan, Y. Xu, P. Yang, H. Zhang, Y. Li and J. Liu, Tetrahedron Lett., 2016, 57, 5385-5389.

11 (a) T. Butler, W. Morris, J. Samonina-Kosicka and C. Fraser, ACS Appl. Mater. Interfaces, 2016, 8, 1242-1251; (b) R. Yoshii, A. Horose, K. Tanaka and Y. Chujo, Chem.-Eur. J., 2014, 20, 8320-8324.

12 W. Liu, Y. Wang, M. Sun, D. Zhang, M. Zheng and W. Yang, Chem. Commun., 2013, 49, 6042-6044.

13 (a) K. Guo, F. Zhang, S. Guo, K. Li, X. Lu, J. Li, H. Wang, J. Cheng and Q. Zhao, Chem. Commun., 2017, 53, 13091312; (b) Y. Zhan, Y. Xu, Z. Jin, W. Ye and P. Yang, Dyes Pigm., 2017, 140, 452-459.

14 Z. Zhang, Z. Wu, J. Sun, B. Yao, Q. Zhang, P. Xue and R. Lu, J. Mater. Chem. C, 2015, 3, 4921-4932.

15 Q. Lu, X. Li, J. Li, Z. Yang, B. Xu, Z. Chi, J. Xu and Y. Zhang, J. Mater. Chem. C, 2015, 3, 1225-1234.

16 P. Wen, Z. Gao, R. Zhang, A. Li, F. Zhang, J. Li, J. Xie, Y. Wu, M. Wu and K. Gao, J. Mater. Chem. C, 2017, 5, 6136-6143.

17 (a) Y. Zhan, J. Peng, K. Ye, P. Xue and R. Lu, Org. Biomol. Chem., 2013, 11, 6814-6823; (b) M. Hranjec, E. Horak, M. Tireli, G. Pavlović and G. karminski-Zamola, Dyes Pigm., 2012, 95, 644-656.

18 P. Xue, B. Yao, P. Wang, J. Sun, Z. Zhang and R. Lu, RSC Adv., 2014, 4, 58732-58739.

19 P. Xue, B. Yao, J. Sun, Q. Xu, P. Chen, Z. Zhang and R. Lu, J. Mater. Chem. C, 2014, 2, 3942-3950.

20 J. N. Zhang, H. Kang, N. Li, S. M. Zhou, H. M. Sun, S. W. Yin, N. Zhao and B. Z. Tang, Chem. Sci., 2017, 8, 577-582.

$21 \mathrm{H}$. Zhao, Y. Wang, S. Harrington, L. Ma, S. Hu, X. Wu, H. Tang, M. Xue and Y. Wang, RSC Adv., 2016, 6, 6647766483. 
22 S. Kaur, A. Gupta, V. Bhalla and M. Kumar, J. Mater. Chem. C, 2014, 2, 7356-7363.

23 P. Xue, J. Ding, Y. Shen, H. Gao and J. Zhao, Dyes Pigm., 2017, 145, 12-20.

24 (a) Y. Zhan, P. Yang, G. Li, Y. Zhang and Y. Bao, New J. Chem., 2017, 41, 263-270; (b) Y. Zhan, P. Gong, P. Yang, Z. Jin, Y. Bao, Y. Li and Y. Xu, RSC Adv., 2016, 6, 32697-32704.

25 F. Qi, J. Lin, X. Wang, P. Cui, H. Yan, S. Gong, C. Ma, Z. Liu and W. Huang, Dalton Trans., 2016, 45, 7278-7284.

26 G. Zhang, J. Sun, P. Xue, Z. Zhang, P. Gong, J. Peng and R. Lu, J. Mater. Chem. C, 2015, 3, 2925-2932.

27 P. Xue, B. Yao, X. Liu, J. Sun, P. Gong, Z. Zhang, C. Qian, Y. Zhang and R. Lu, J. Mater. Chem. C, 2015, 3, 1018-1025.

28 J. Zhang, J. Chen, B. Xu, L. Wang, S. Ma, Y. Dong, B. Li, L. Ye and W. Tian, Chem. Commun., 2013, 49, 3878-3880.
29 (a) Y. Zhan, J. Zhao, P. Yang and W. Ye, RSC Adv., 2016, 6, 92144-92151; (b) Z. Wu, J. Sun, Z. Zhang, P. Gong, P. Xue and R. Lu, RSC Adv., 2016, 6, 97293-97301.

30 P. Xue, B. Yao, J. Sun, Z. Zhang, K. Li, B. Liu and R. Lu, Dyes Pigm., 2015, 112, 255-261.

31 L. Mosca, R. S. Khnayzer, M. S. Lazorski, E. O. Danilov, F. N. Castellano and P. Anzenbacher, Chem.-Eur. J., 2015, 21, 4056-4064.

32 H. J. Lim, C. H. Heo and H. M. Kim, J. Am. Chem. Soc., 2013, 135, 17969-17977.

33 G. Sevinç, B. Küçüköz, H. Ylmaz, G. Şirikçi, H. G. Yaglioglu, M. Hayvali and A. Elmali, Sens. Actuators, B, 2014, 193, 737744.

34 Li, L.-J. Li, T. Sun, L. Liu and Z. Xie, Dyes Pigm., 2016, 128, 165-169. 